\title{
Antibiotic Prescription and Bacterial Resistance
}

\author{
Farideh Shiva ${ }^{1, *}$ \\ ${ }^{1}$ Pediatric Infections Research Center, Mofid Children's Hospital, Shahid Beheshti University of Medical Sciences, Tehran, IR Iran \\ *Corresponding author: Farideh Shiva, Pediatric Infections Research Center, Shahid Beheshti University of Medical Sciences, Tehran, IR Iran. Tel:+98-9126789986, E-mail: faridehshiva@gmail.com
}

Received: June 25, 2014; Accepted: July 6, 2014

Keywords: Antibiotics; Bacterial; Resistance; Culture; Infection

"The first rule for antibiotics is to try not to use them, and the second rule is to try not to use too many of them" (1). Since Alexander Fleming's accidental discovery of penicillin that has saved millions of lives for almost a century, antibiotics have been used, misused and over-used time after time resulting in widespread antimicrobial resistance, a phenomenon that has been recognized by the World Health Organization as a global crisis (2). In 1946 Fleming predicted antibiotic abuse and emergence of bacterial resistance, hoping that this inevitable calamity could be prevented; in his words "the thoughtless person playing with penicillin treatment is morally responsible for the death of the man who finally succumbs to infection with the penicillin resistant organism" (3). Regrettably, Fleming's prophecy has come true and clinicians have seen a rapidly increasing rate of bacterial resistance to different antimicrobials during the recent decades. Resistance to the commonly used $\beta$-lactam antibacterials, including cephalosporins and carbapenems, which target bacterial cell wall synthesis, is mediated through enzymes called $\beta$-lactamases that hydrolyze the $\beta$-lactam ring. The last decade has witnessed the emergence of multi-resistant bacterial strains bearing extended spectrum $\beta$-lactamases and, most importantly a new enzyme, namely the New Delhi metallo- $\beta$-lactamase or NDM-1; some strains of this enzyme can hydrolyze all known $\beta$-lactam antibiotics (4). Although bacterial resistance could partly be attributed to an evolutionary process, indiscriminate and irrational prescription practices have played a large part in its rapid escalation. Numerous studies have documented irrational antibiotic prescription patterns globally; examples of antibiotic misuse include unnecessary prescription, using inappropriate antibiotics, administration of broadspectrum and second line antibiotics for bacteria susceptible to a narrow spectrum antimicrobial, incorrect dosing, incorrect duration, delaying antibiotic treatment in seriously ill patients, and a failure to move to targeted therapy when culture results are available (5). Another major problem is the prophylactic use of anti-microbial drugs in surgical and dental practice and for prevention of bacterial infections in patients with viral respiratory tract illnesses. In the majority of cases use of prophylactic antibiotics is not evidence-based and relies on personal or traditional beliefs.

Since the threat of infection with 'superbugs', carrying strains that make them resistant to most antibiotics, is increasing and since the development and approval of new antibiotics has declined during the recent years, concerned authorities are adopting resistance control policies to impede the rise of pan-resistant strains. These multi-faceted strategies are composed of different approaches including increasing public awareness, training health professionals in adherence to hand hygiene and antimicrobial stewardship programs to improve the quality of prescriptions (6). Various campaigns for public and professional information have started in different countries; in France the program is called "antibiotics are not automatic"; in the USA, "get smart" and in Canada "do bugs need drugs?" (2). The CDC program named "get smart know when antibiotics work" not only provides general guidelines about antibiotic usage, but also gives tips on how to counsel patients and parents about rational use of antimicrobial medications at 'well child' visits and handle situations when patients insist on prescription of antibiotics for common viral infections like 'sore throats' (7). Antibiotic stewardship, (ASP), is a comprehensive program that promotes appropriate and prudent antimicrobial usage, thus reducing the emergence of resistant microorganisms and improving patient outcomes. Microbiological, biochemical, pharmacokinetic, and pharmacodynamic data could be utilized in making rational treatment decisions $(6,8)$. Diagnostic laboratory tests like the measurement of procalcitonin levels may differentiate viral illnesses from bacterial infections, and rapid culture results with antibiograms can be used to tailor antibiotics according to the sensitivity patterns of the isolated pathogen (3, 8-10). In addition, using shorter courses of antibiotics and switching from intravenous

Copyright (C) 2015, Pediartric Infections Research Center. This is an open-access article distributed under the terms of the Creative Commons Attribution-NonCommercial 4.0 International License (http://creativecommons.org/licenses/by-nc/4.0/) which permits copy and redistribute the material just in noncommercial usages, provided the original work is properly cited. 
to oral route limits the duration of exposure (3). Various controlled trials have revealed that short courses were as effective as the so-called standard courses in pyelonephritis, ventilator associated pneumonia, septic arthritis, and community acquired pneumonia (3).

Even if all hospitals do not follow the formal ASP, most hospitals use some form of infection control technique; however, since a large number of inappropriate usage is in outpatient practices, especially in children with acute viral infections, researchers have studied the effect of brief educational sessions for clinicians about appropriate antibiotic usage and have found these to be effective in improving the quality of prescriptions (11). One option is to use 'watch and wait' policies and to write delayed prescriptions; for example in $>2$ years old children with acute otitis media, guidelines recommend antibiotics only in selected cases, or in immune competent children with coughs, a watch and wait policy usually averts the unnecessary use of antimicrobials (7). Another relatively common malpractice is to use antibiotics in lieu of antipyretics, especially in the pediatric population (12). As fever is a frequent and often self-limiting complaint in children, alarmed parents often request antibiotics; it is the family physician's/pediatrician's task to reassure and inform parents about useless medical intervention. Antipyretics may be prescribed, but only if necessary $(7,12)$. It is our moral responsibility to safeguard antimicrobials for future generations; if the present inappropriate, irrational, unnecessary and mass abuse of antibiotics continues we will be back in the pre-antibiotic era and may see human beings dying of infections that cannot be treated with any antibiotic.

\section{References}

1. Marino PL. Antimicrobial therapy:: Lippincott Williams \& Wilkins; 2007.

2. World Health Organization. WHO. Bulletin of the World Health Organization Antimicrobial resistance: revisiting the "tragedy of the commons". 2010.

3. Bartlett JG, Gilbert DN, Spellberg B. Seven ways to preserve the miracle of antibiotics. Clin Infect Dis. 2013;56(10):1445-50.

4. Kim Y, Cunningham MA, Mire J, Tesar C, Sacchettini J, Joachimiak A. NDM-1, the ultimate promiscuous enzyme: substrate recognition and catalytic mechanism. FASEB J. 2013;27(5):1917-27.

5. Dryden M, Johnson AP, Ashiru-Oredope D, Sharland M. Using antibiotics responsibly: right drug, right time, right dose, right duration. J Antimicrob Chemother. 2011;66(11):2441-3.

6. O'Brien DJ, Gould IM. Maximizing the impact of antimicrobia stewardship: the role of diagnostics, national and international efforts. Curr Opin Infect Dis. 2013;26(4):352-8.

7. Centers for Disease Control and Prevention. Get Smart Know When Antibiotics Work. CDC; 2014.

8. Davey P, Brown E, Charani E, Fenelon L, Gould IM, Holmes A, et al. Interventions to improve antibiotic prescribing practices for hospital inpatients. Cochrane Database Syst Rev. 2013; 4:CD003543.

9. Wickens HJ, Farrell S, Ashiru-Oredope DA, Jacklin A, Holmes A, Antimicrobial Stewardship Group of Department of Health Advisory Committee on Antimicrobial R, et al. The increasing role of pharmacists in antimicrobial stewardship in English hospitals. $J$ Antimicrob Chemother. 2013;68(11):2675-81.

10. Schuetz P, Raad I, Amin DN. Using procalcitonin-guided algorithms to improve antimicrobial therapy in ICU patients with respiratory infections and sepsis. Curr Opin Crit Care. 2013;19(5):453-60.

11. Gerber JS, Prasad PA, Fiks AG, Localio AR, Grundmeier RW, Bell LM, et al. Effect of an outpatient antimicrobial stewardship intervention on broad-spectrum antibiotic prescribing by primary care pediatricians: a randomized trial.JAMA. 2013;309(22):2345-52.

12. Elshout G, Kool M, Van der Wouden JC, Moll HA, Koes BW, Berger MY. Antibiotic prescription in febrile children: a cohort study during out-of-hours primary care. J Am Board Fam Med. 2012;25(6):810-8. 